Article

\title{
Determining the Pull-Forces Required to Extricate a Victim Entrapped at Various Angles in a Grain Mass
}

\author{
Salah F. Issa * and William E. Field
}

Agricultural and Biological Engineering, Purdue University, West Lafayette, IN 47907, USA; field@purdue.edu

* Correspondence: issa0@purdue.edu or salahfuadissa@gmail.com; Tel.: +1-201-618-0482

Academic Editor: Dennis Murphy

Received: 1 July 2016; Accepted: 7 March 2017; Published: 11 March 2017

\begin{abstract}
Prior research on extrication of victims entrapped in stored grain has measured the vertical forces applied to a representative victim (i.e., mannequin) using an anchor point that is mounted directly overhead. However, primarily because of how most grain storage structures are designed, the forces applied would more likely be coming from an angle. This is due to the victim typically being entrapped in the center of the grain mass while the access point is at the perimeter of the roof. The objective of this study was to measure the peak forces required to pull a mannequin at an angle and compare it to vertical pull. An adult-size mannequin was pulled out of dry corn and soybean masses from various depths and at various angles. It was found that both corn and soybeans were comparable regardless of depth or angle with the exception of $15^{\circ}$ angle. It was also found that, at pulling angles of $60^{\circ}$ and $75^{\circ}$, the loads were comparable to those required at $90^{\circ}$ or directly overhead. Only at the sharper angles of $15^{\circ}$ and $30^{\circ}$ did the peak forces significantly increase. The results highlight that there is some flexibility in the placement of the anchor point and that extrication forces on the body will increase at sharper pull angles.
\end{abstract}

Keywords: vertical pull; angle pull; grain entrapment; grain extrication; grain engulfment; anchor points

\section{Introduction}

Grain entrapments and engulfments continue to be an important issue on farms and at grain storage facilities across the U.S. On average, about 35 such incidents have occurred per year over the last ten years [1]. In one of the first research studies on grain entrapment, Schmecta and Matz [2] sought to determine the speed at which a human subject becomes buried in grain and the depth at which self-extrication is no longer possible in a bottom-unloading test bin. They found that (1) it took only about $30 \mathrm{~s}$ for one to get entrapped to shoulder level with grain flowing out at 25 metric tons per hour (925 bushels per hour); (2) at hip level, self-extrication was not possible, but extrication could be accomplished with the aid of another individual; and (3) at shoulder depth, not only was self-extrication impossible, but also the safety harness employed for the test was damaged when the subject was being pulled out by rope, and the test had to be discontinued because of the pain caused to the victim by the rescue effort.

Schwab et al. [3] expanded upon this study by measuring the total force that the body experiences at various depths during extrication. Using a $75 \mathrm{~kg}$ (165 lbs.) mannequin to represent an adult victim, they found that it "experienced" about $2700 \mathrm{~N}(\sim 600 \mathrm{lbf})$ at shoulder depth and $1300 \mathrm{~N}(\sim 300 \mathrm{lbf})$ at waist level. Similarly, Roberts et al. [4] found that a mannequin experiences about $1770 \mathrm{~N}$ ( 400 lbf) and $1260 \mathrm{~N}$ ( $\sim 280 \mathrm{lbf})$ when pulled from armpit and waist levels, respectively. The same study also showed that, upon insertion of a coffer dam (or grain rescue tube), the peak force required to extricate the mannequin increased by $24 \%$. 
Earlier, Roberts et al. [5] reported a case study in which a co-worker attempted to extricate an entrapped victim by tying one end of a rope around their (the victim's) chest, running the rope outside the grain bin and tying the other end to a pickup truck, then driving the truck away from the bin in an effort to pull the victim out. The victim ended up suffering fatal injuries due to the forces applied on their body, which begs the questions: Did pulling the victim at an angle increase the total force on their body and, if so, do these forces exceed the human capacity to survive them? The study presented here sought to expand on previous research by testing the amount of force required to extricate a mannequin out of grain at various angles.

\section{Materials and Methods}

Two grains were used in this experiment-soybeans and corn, by far the most common mediums involved in grain entrapment incidents [6]. Samples of each were taken and their properties tested. Three samples were taken randomly and mixed together into a larger sample. Moisture content measurements were based on ASABE Standard S352.2 [7]; and bulk density was determined by filling a $0.55 \mathrm{~L}$ cup using a funnel, leveling the surface, and then measuring the weight of the grain [8]. Three random samples were used for bulk density, and five samples were used for moisture content measurements.

\subsection{Experiment Setup}

The study was conducted at a grain elevator in Maquon, Illinois. A bin, measuring $2.4 \mathrm{~m}(8 \mathrm{ft})$

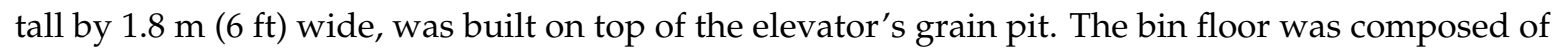
plywood sheets, except for a $33 \times 33 \mathrm{~cm}$ (13 in.) metal slide gate in the middle (Figure 1). The bin drained by gravity into the pit and was filled by the elevator leg, which had a maximum rate of about 7000 bushels per hour. An overhead anchor point was placed as close to the center of the bin as possible.

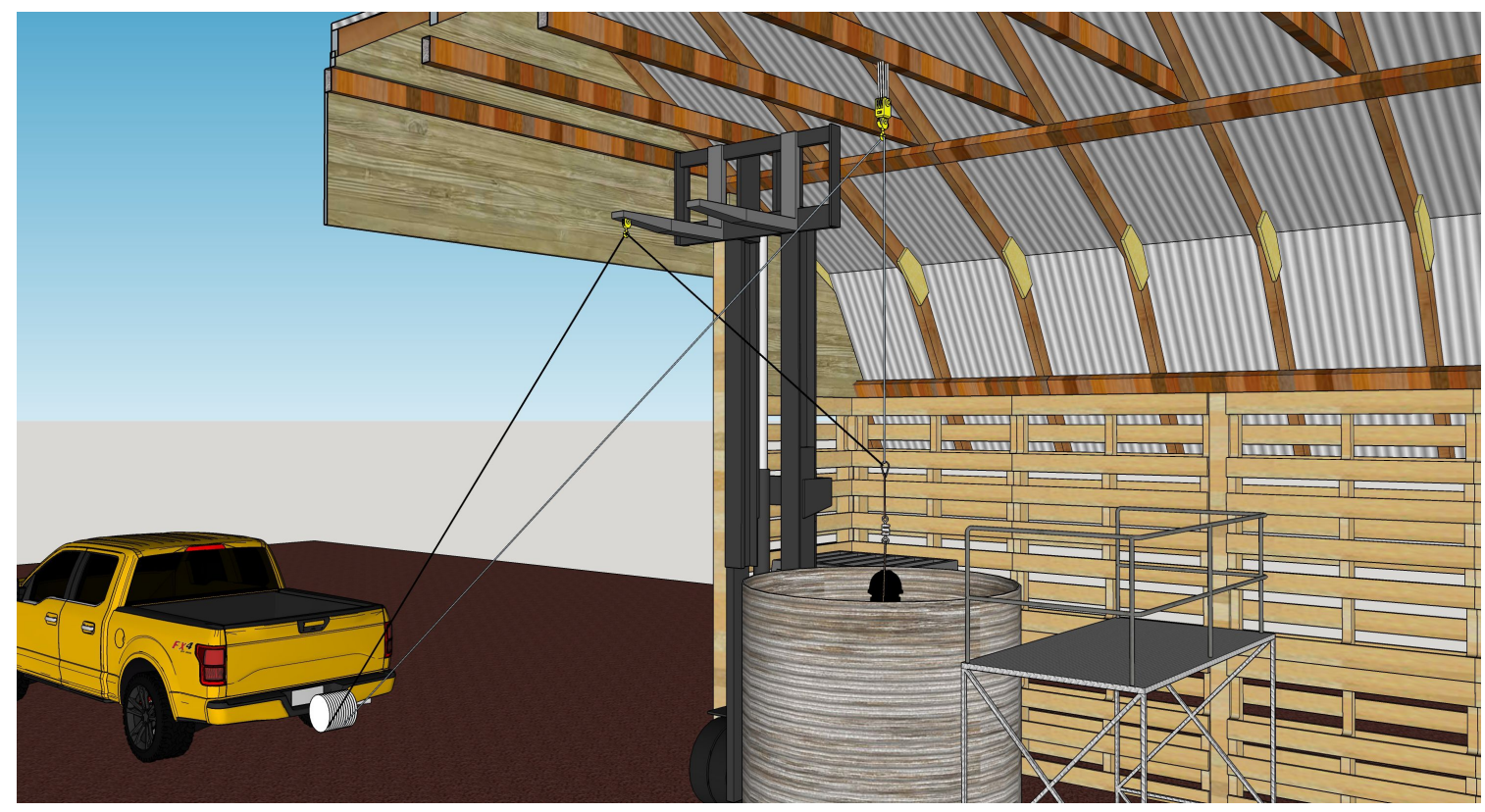

Figure 1. Experimental setup showing location of mechanical winch, forklift (angle anchor point), vertical anchor point, and observation deck. Grain bin was located on top of grain pit and below grain loading output (not shown).

The mannequin was $75 \mathrm{~kg}$ (165 lbs.), measured $185 \mathrm{~cm}$ (73 in.) from the base of its feet to the top of its head and had articulated joints (Rescue Randy, Simulaids Inc., New York, NY, USA). It was 
dressed in a flannel shirt, bib overalls, and pull-on boots. A full-body, ANSI-rated safety harness with back-mounted D-ring was placed on the mannequin to serve as the point of attachment for the load cell (Figure 2, left). The mannequin with clothes, boots, harness, and attachments for the load cell weighed $82 \mathrm{~kg}(180 \mathrm{lb}$.).

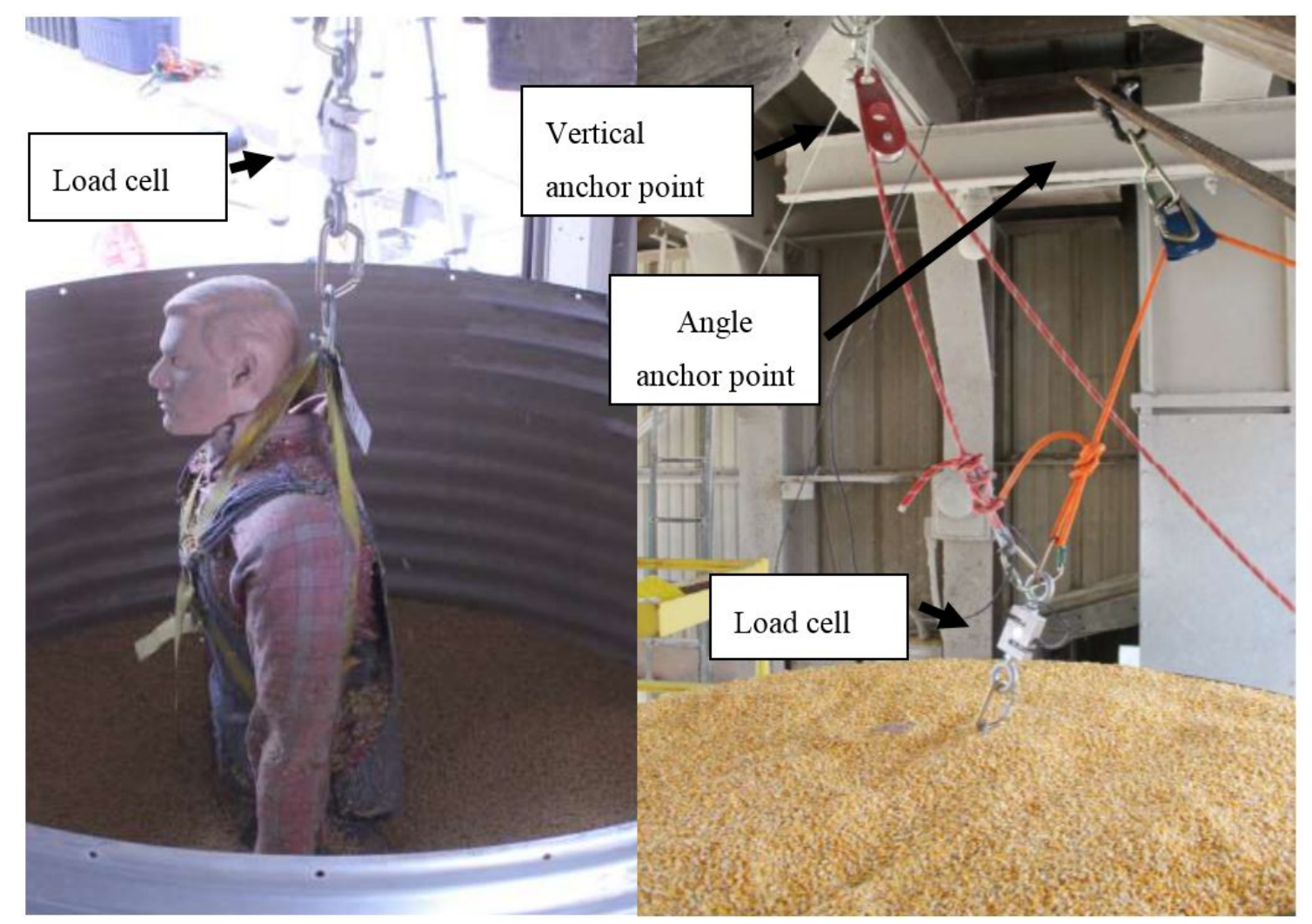

Figure 2. Mannequin setup for experiment shown on the left. On the right, the mannequin is fully engulfed in grain and tied to two lines for vertical pull and angle pull.

The load cell (ICS516, Industrial Commercial Scales, North Charleston, SC, USA) was rated for $44 \mathrm{kN}(10,000 \mathrm{lbf})$ and was attached through a pulley system to a winch rated for $454 \mathrm{~kg}$ (1000 lbs.). The cell is maintained by the grain elevator (Maquon, IL, USA). A simple verification on the cell was conducted by measuring a $590 \mathrm{~kg}$ (1300 lbs.) concrete block and was found to accurately measure the block within $1 \%$. On the lower end, the mannequin weight was used as a verification and was found to accurately measure the mannequin weight within $2 \%$. It was set up to output only the peak load during each run. Two lines were attached to the cell, one for a vertical pull and the other for an angle pull (Figure 2, right). Only one of those lines was attached to the winch at a time.

A fork lift truck was used as an anchor point for the angle line in order to be able to change the angle based on the experimental design. Each angle was measured and calibrated to the prescribed degree after the mannequin was buried in the grain, and the line was tightened via the winch. A hand-held magnetic angle finder was used to determine each test angle.

\subsection{Experiment Design}

This experiment involved two parts-tests to determine the forces required for extrication from various depths when pulling vertically and tests to determine the forces required for extrication when pulling from various angles. A two tailed $t$-test analysis was conducted between each depth, angle and grain type at $p<0.05$. Only the peak force was recorded for both tests. The peak force values were used since the authors were interested in the upper limit of force experienced by the body. A potential 
limitation of using only the peak force is that it may be recorded incorrectly due to a sudden peak due to the locking of mechanical parts. This limitation was not observed in this study.

\subsubsection{Vertical-Pull Experiment}

This was similar to that conducted by Schwab et al. [3], with five grain depths chosen-two to represent full engulfment (grain levels at $38 \mathrm{~cm}$ (15 in.) above the head and at the top of the head), and three to represent entrapment (grain levels at shoulder, chest, and waist). The mannequin had been marked at each depth to ensure that it was buried at that depth. The experiment included these sequential steps: (1) the mannequin is placed in the test bin at almost shoulder level; (2) the bin is filled with grain to its rim; (3) the slide gate opens and the mannequin is allowed to sink into the grain until the $38 \mathrm{~cm}$ marker above the head reaches the same level as the rim; (4) the bin is again filled and the grain is leveled with a rake; (5) the mannequin is then pulled straight up at a rate of $4.2 \mathrm{~m} / \mathrm{min},(13.6 \mathrm{ft} / \mathrm{min})$ to about $0.3-0.6 \mathrm{~m}(1-2 \mathrm{ft})$ above the rim, with the load cell recording the peak load; (6) the load cell is reset; (7) the slide gate is opened again until the mannequin sinks to the second marker (i.e., top of head); (8) the bin is filled again and the grain is leveled against the marker; (9) Steps 1-8 are repeated until peak load measurements are recorded for shoulder-, chest-, and waist-level positions; (10) the entire experiment is repeated two more times, totaling three replications; and (11) lastly, the mannequin is weighed to confirm that it was within the initial range of $82 \mathrm{~kg}$ and the load cell remains correctly calibrated.

\subsubsection{Angled-Pull Experiment}

The design of this experiment was similar to the vertical-pull test but with the following differences: (1) after the mannequin is engulfed in a vertical position, the pull lines are switched to allow it to be pulled out at an angle; (2) the mannequin is buried at only one depth-the top of the head; (3) the pull line is set at an angle $\left(15^{\circ}, 30^{\circ}, 45^{\circ}, 60^{\circ}\right.$, or $\left.75^{\circ}\right)$ and the mannequin is pulled out at that angle; (4) the peak load is recorded, and the line is switched to the vertical line again; (5) the mannequin is pulled further upwards until vertical again; (6) the mannequin is engulfed again and the experiment is repeated; and (7) Steps 1-6 are repeated twice at each angle (totaling three replications for each angle) before moving on to the next angle. (Note: At the sharper angles (i.e., $15^{\circ}$ and $30^{\circ}$ ), the bin was drained between runs to make sure that the methods did not impact the results, and no appreciable difference was found between draining the bin completely and partially as mentioned above.)

\section{Results}

\subsection{Grain Properties}

The bulk density of corn and soybeans used in this study was $754.25 \mathrm{~kg} / \mathrm{m}^{3}$ (St. Dev. $=7.45$ ) and $749.76 \mathrm{~kg} / \mathrm{m}^{3}$ (St. Dev. $=1.14$ ), respectively. Moisture content of the corn was $13.3 \%$ and of the soybeans was $9.9 \%$. Both grains were below the maximum moisture levels desirable for long-term storage.

\subsection{Vertical-Extrication Tests}

Table 1 shows the amounts of pull-force required to free the mannequin entrapped vertically (upright) in the corn and the soybean grain masses at the five different depths (i.e., $38 \mathrm{~cm}$ above-head, head, shoulder, chest, and waist levels). The last measurement point $(0.0 \mathrm{~m})$ shown in the table is the mannequin held freely by the load cell.

For both the corn and the soybean entrapments/engulfments, the measurements at these five depth levels were significantly different from each other at $p<0.05$. However, the recorded measurements between the two grains were not significantly different at any depth (Figure 3). 
Table 1. Peak extrication force (in newtons $\mathrm{w} /$ standard deviations) required to free the mannequin entrapped vertically in corn and in soybeans at specified depth levels.

\begin{tabular}{cccccc}
\hline & & \multicolumn{2}{c}{ Corn } & \multicolumn{2}{c}{ Soybeans } \\
\hline & Grain Depth $^{\mathbf{1}} \mathbf{( m )}$ & Pull Force (N) & St. Dev. (N) & Pull Force (N) & St. Dev. (N) \\
\hline Above Head & 2.24 & 4653 & 154 & 4875 & 471 \\
Head & 1.85 & 3072 & 116 & 3010 & 74 \\
Shoulder & 1.57 & 2331 & 79 & 2337 & 37 \\
Chest & 1.35 & 1913 & 62 & 1928 & 27 \\
Waist & 1.07 & 1690 & 27 & 1741 & 10 \\
Mannequin & 0.0 & 817 & 19 & 818 & 9 \\
\hline
\end{tabular}

${ }^{1}$ Distance from the grain surface to the bottom of the mannequin feet.

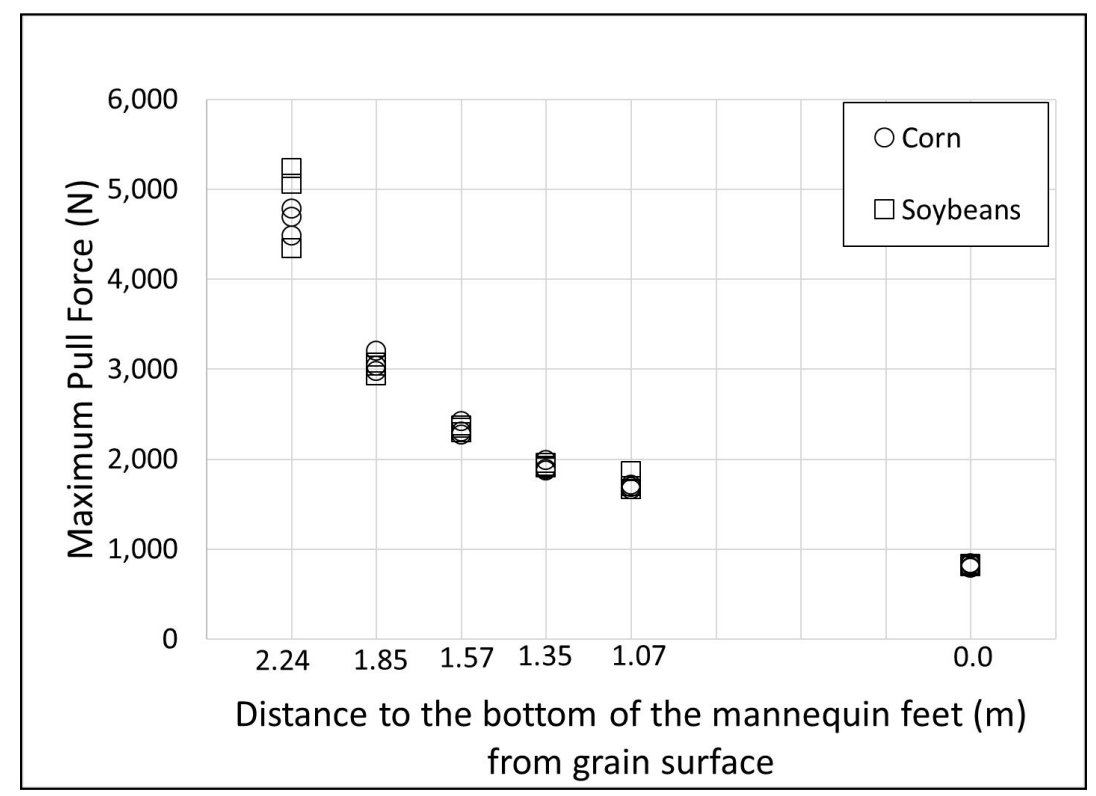

Figure 3. Maximum pull-force (in newtons) required to extricate the mannequin vertically at various depths in corn (circle) and soybeans (square).

\subsection{Angled-Extrication Tests}

Table 2 shows the amount of pull-forces required to free the mannequin entrapped to the top-of-the-head level in the corn and the soybean grain masses at five different angles (i.e., $15^{\circ}$, $30^{\circ}, 45^{\circ}, 60^{\circ}$, and $\left.75^{\circ}\right)$ and compared to the vertical $\left(90^{\circ}\right)$ pull results.

Table 2. Peak extrication force (in newtons $\mathrm{w} /$ standard deviation) required to free the mannequin entrapped at specific angles in corn and soybeans at a depth of $1.85 \mathrm{~m}$.

\begin{tabular}{ccccc}
\hline & \multicolumn{2}{c}{ Corn } & \multicolumn{2}{c}{ Soybeans } \\
\hline Angle $\left.\mathbf{(}^{\circ}\right)$ & Pull Force $^{\mathbf{1}} \mathbf{( N )}$ & St. Dev. (N) & Pull Force $^{\mathbf{1}} \mathbf{( N )}$ & St. Dev. (N) \\
\hline $\mathbf{1 5}$ & $4416^{\mathrm{a}}$ & 123 & $3748^{\mathrm{a}}$ & 85 \\
$\mathbf{3 0}$ & $3716^{\mathrm{a}}$ & 31 & $3891^{\mathrm{a}}$ & 149 \\
$\mathbf{4 5}$ & $3413^{\mathrm{b}}$ & 59 & $3496^{\mathrm{b}}$ & 50 \\
$\mathbf{6 0}$ & $3298^{\mathrm{bc}}$ & 116 & $3348^{\mathrm{bc}}$ & 89 \\
$\mathbf{7 5}$ & $3126^{\mathrm{c}}$ & 36 & $3072^{\mathrm{c}}$ & 72 \\
$\mathbf{9 0}$ & $3072^{\mathrm{c}}$ & 116 & $3010^{\mathrm{c}}$ & 74 \\
\hline
\end{tabular}

\footnotetext{
${ }^{1}$ Pull forces with the same letter are not significantly different from each other $(p<0.05)$ regardless of grain type.
} 
For the corn entrapments, (1) the pull-forces involved at angles of $60^{\circ}$ and $75^{\circ}$ were not significantly different from each other or from those of the vertical-extrication $\left(90^{\circ}\right)$ tests at the same depth; (2) the pull force at $45^{\circ}$ angle was not significantly different from the $60^{\circ}$ angle but was significantly different from the $75^{\circ}$ and $90^{\circ}$ angles; and (3) the $15^{\circ}$ and $30^{\circ}$ angles were significantly different at $p<0.05$ from all other angles (Figure 4 ). As the angle was decreased there was a corresponding increase in the peak forces required to extricate the mannequin.

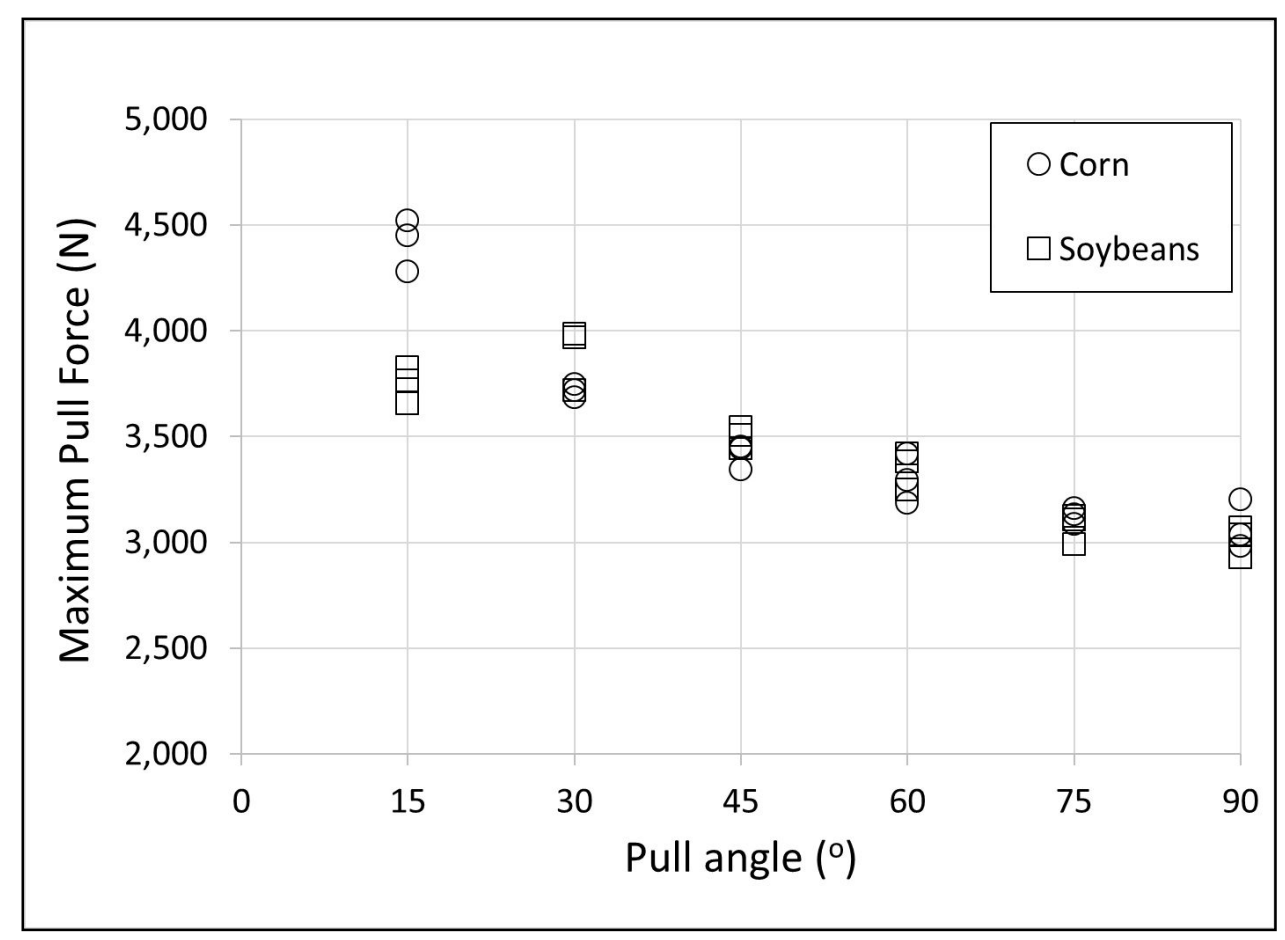

Figure 4. Maximum pull-force (in newtons) required to extricate the mannequin at various angles at a $1.8 \mathrm{~m}$ depth in corn (circle) and soybeans (square).

For the soybean entrapments, the pull force was not significantly different between (a) the $60^{\circ}, 75^{\circ}$, and $90^{\circ}$ angles; (b) the $45^{\circ}$ and $60^{\circ}$ angles; and (c) the $15^{\circ}$ and $30^{\circ}$ angles. Pull force values for all other angle combinations were significantly different from each other at $p<0.05$. The measurements between corn and soybeans were not significantly different at angles of $30^{\circ}, 45^{\circ}, 60^{\circ}, 75^{\circ}$, and $90^{\circ}$, but they were for the $15^{\circ}$ angle at $p<0.05$ (Figure 4). As for corn, the required peak forces for extrication increased as the angle of the pull was reduced.

\section{Discussion}

\subsection{Comparison with the Schwab et al. Study Results}

The vertical-extrication test was conducted to validate this present study's experimental methods by comparing the results with those from the study by Schwab et al. [3] and Roberts et al. [4]. Although not an exact comparison between the two studies (due to grain properties, fine material, grain bin size and grain depth), this study's pull-force values at similar depths (with the exception of $1.85 \mathrm{~m}$ depth) were within one standard deviation from Schwab et al. [4] pull-force values (Table 3).

Two interesting results emerge from this comparison. The first one is that the vertical-pull experiment ended up with a significantly smaller standard deviation between the runs than what was reported in the Schwab et al. study. Among the possible explanations are the effect of leveling the grain and/or the limited number of runs conducted in this study. In contrast to this experiment in which the grain was leveled before each pull, Schwab et al. did not level the grain after engulfing the 
mannequin, but rather kept the grain mass's natural inverted conical shape. While this perhaps is more appropriate since victims will likely not be entrapped in level grain, it also seems to produce more "noise," as it is hard to ensure that the mannequin is at the bottom of the inverted cone during every run. The second interesting result is that the vertical-test averages were almost always lower than Schwab et al. at the same grain depth. This may also be due to the leveling of the grain, because it reduces the pressure that the extra mass in the inverted cone indirectly places on the body. However, leveling the grain was still an important method since it allows for highly repeatable results. The only times the pull force in this study was significantly larger than Schwab et al. [3] and Roberts et al. [4] were due to the placement of the waist marker, which was 13 and $16 \mathrm{~cm}$ higher, respectively.

Table 3. Comparison between the current study and the Schwab et al. study results for vertical-force pull.

\begin{tabular}{|c|c|c|c|c|c|c|c|}
\hline \multicolumn{2}{|c|}{ Current-Study Results } & \multicolumn{3}{|c|}{ Schwab et al. Study Results } & \multicolumn{3}{|c|}{ Roberts et al. Study Results } \\
\hline $\begin{array}{c}\text { Grain } \\
\text { Depth (m) }\end{array}$ & $\begin{array}{c}\text { Pull } \\
\text { Force (N) }\end{array}$ & $\begin{array}{c}\text { Grain } \\
\text { Depth }(m)\end{array}$ & $\begin{array}{c}\text { Pull } \\
\text { Force (N) }\end{array}$ & St. Dev. & $\begin{array}{c}\text { Grain } \\
\text { Depth (m) }\end{array}$ & $\begin{array}{c}\text { Pull } \\
\text { Force (N) }\end{array}$ & St. Dev. \\
\hline 2.24 & 4652 & 2.20 & 5253 & 903 & & & \\
\hline 1.85 & 3072 & 1.89 & 4012 & 765 & & & \\
\hline 1.57 & 2331 & 1.58 & 2771 & 583 & & & \\
\hline 1.35 & 1913 & 1.26 & 1913 & 360 & 1.37 & 1766 & 200 \\
\hline 1.07 & 1690 & 0.94 & 1321 & 196 & 0.91 & 1259 & 71 \\
\hline
\end{tabular}

\subsection{Influence Due to Grain Type}

In both the vertical-pull and the angle-pull experiments, the results recorded in corn and those in soybeans were not significantly different from each other, except for the $15^{\circ}$-angle test. This was an unexpected finding, since the two grains were chosen because they have different shapes; thus, it was assumed they would behave differently. The fact that they behaved similarly was perhaps because of their similar bulk densities. In a study on grain pressure on the chest, Moore and Jones [9] likewise found the differences in the corn and soybean results to be insignificant. Concerning the difference recorded between the two grains at the $15^{\circ}$ angle, it might have been due to a limitation that occurred in the experiment setup. Installation of the anchor point at the very low angle of $15^{\circ}$ was difficult and was slightly modified by adjusting the forklift location (angle anchor point) between running the soybean and corn experiments. Applying extrication forces to an actual victim at such low angles would be most unlikely. Another potential cause for the difference in pull-force might be due to the grain size/shape. While the bulk density of grain (thus the weight of grain) dominates during vertical pull, as the angle is adjusted the shape and grain-grain friction will play a more dominate role and might thus be the cause in the difference in the pull-force values.

\subsection{Angle Extrication Test Results}

Results showed that the mannequin could be extricated from as sharp an angle as $60^{\circ}$ without significantly impacting the pull-force required. Pulling the mannequin at $15^{\circ}$ and $30^{\circ}$ angles made a significant difference in the maximum force needed to free the mannequin in comparison to vertical pull. At $15^{\circ}$ for corn (1.85 $\mathrm{m}$ depth), the pull force was not significantly different from pulling a mannequin at $2.24 \mathrm{~m}$ depth level (from surface of grain to feet). These findings suggest that, relative to placement of the overhead anchor points, some flexibility apparently is possible in rescue situations. However, it is important to note that, compared to a straight vertical pull, additional time was required to extricate the mannequin when set up at various anchor point angles. Time was not a measured parameter; it was observed that it took more time to pull the mannequin out of grain than in a vertical extrication. 


\subsection{Risk of Injury during Forceful Extrication}

With the force required to pull the mannequin at $38 \mathrm{~cm}$ below grain mass found to be about five and a half times greater than the mannequin's weight, it is highly likely that such force would cause serious harm to one's spine and joints. Similarly, attempts to forcibly free a victim with the anchor point located at angles below $45^{\circ}$, may also result in injury. The problem becomes even more critical if the victim is not wearing a body harness that is capable of distributing the pull force over a larger portion of their body, as was often found to be the case as reported by Roberts et al., [5] and Issa and Field [10]. It remains difficult to specify the point at which depth and/or angle would cause injury, especially due to the variability of victims in past entrapments. These incidents have involved victims as young as 2 and as old as 80 years of age [1]. Physical conditions such as previous joint replacements, physical strength, levels of obesity, and heart condition could increase the risk of secondary injury during extrication. Thus, the safest recommendation is to avoid vertical extrication until more research is done on the ability of the body, especially the spine, to handle tensile loads required for extrication.

\section{Conclusions}

The results of this study confirmed that (1) a large pull-force is required to extricate someone entrapped in a grain mass, and (2) pulling the victim at an angle sharper than $45^{\circ}$ results in substantially greater forces being applied to the body. One positive finding from this research, however, was that emergency first responders and grain bin manufacturers do have some leeway in the placement of anchor points; that is, it does not have to be exactly vertical to the center of the bin. This leeway could allow bin manufacturers to meet the Occupational Safety and Health Administration (OSHA) design criteria for anchor points for fall protection $(22,200 \mathrm{~N}$ or $5000 \mathrm{lbf})$ [11] on structures having roofs with low load capacities.

It is recommended that the content of the emergency first responder training be updated to include the following information: (1) Based upon case studies, the forces required to forcefully extricate an entrapped victim can potentially exceed that which the body can endure; (2) the use of extrication strategies that separate the victim from the grain, such as using a grain rescue tube or comparable coffer dam that allows the grain to be removed from around the victim provide for the least force being administered to the victim during rescue attempts [4]; (3) extrication angles can make a difference in the amount of required force on the body; (4) rescue anchor points can be located at up to $30^{\circ}$ off the center of the storage structure and be used without significantly increasing the forces required for extrication; (5) anchor points at lower angles will produce greater force increasing the risk of injury to the victim; and (6) rescuers should not assume that using structural components as anchor points can be used for extraction.

It is also recommended that additional research be conducted on ascertaining the physiological responses that occur during extrication, including the forces on the body and the pressures on internal organs.

Acknowledgments: Special thanks to Lynn McClure, Mark Johnson, David Newcomb, John Lee, and Kris Richardson for their contributions in the setup and completion of this experiment. Additionally, thanks to Hermon Elevator in Maquon, IL, for use of their facility and equipment necessary to conduct this experiment. This research was partially funded by Purdue Graduate Student Government Research Grant and Purdue Agricultural Safety and Health Program. Special thanks to Ibrahim Issa for providing schematic diagram of experimental setup (Figure 1).

Author Contributions: S.I. and W.F. conceived and designed the experiments; S.I. performed the experiments; S.I. and W.F. analyzed the data; S.I. wrote the paper.

Conflicts of Interest: The authors declare no conflict of interest.

\section{References}

1. Issa, S.F.; Cheng, Y.H.; Field, W.E. Summary of agricultural confined-space related cases: 1964-2013. J. Agric. Saf. Health 2016, 22, 33-45. [PubMed] 
2. Schmechta, V.; Matz, A. Zum Versinken in Getreide [About engulfment in grain]. Zeitschrift für die Gesamte Hygiene und Ihre Grenzgebiete 1971, 17, 565-567. [PubMed]

3. Schwab, C.V.; Ross, U.; Piercy, L.; McKenzie, B.A. Vertical pull and immersion velocity of mannequins trapped in enveloping grain flow. Trans ASAE 1985, 28, 1997-2002.

4. Roberts, M.; Field, W.; Maier, W.; Stroshine, R. Determination of entrapment victim extrication force with and without use of a grain rescue tube. J. Agric. Saf. Health 2015, 21, 71-83. [PubMed]

5. Roberts, M.J.; Deboy, G.R.; Field, W.E.; Maier, D.E. Summary of prior grain entrapment rescue strategies. J. Agric. Saf. Health 2011, 17, 303-325. [CrossRef] [PubMed]

6. Issa, S.F.; Cheng, Y.H.; Field, W.E. 2015 Summary of U.S. Agricultural Confined Space-Related Injuries and Fatalities; Purdue University Agricultural Safety and Health Program; Purdue University: West Lafayette, IN, USA, 2016.

7. American Society of Agricultural and Biological Engineers (ASABE). Moisture Measurement-Unground Grain and Seeds; ASABE: St. Joseph, MO, USA, 2012.

8. Clementon, C.; Ileleji, K.; Rosentrater, K. Evaluation of measurement procedures used to determine the bulk density of distillers dried grains with solubles (DDGS). Trans ASABE 2010, 53, 485-490. [CrossRef]

9. Moore, K.G.; Jones, C. Pressure on the torso during grain entrapment and possible physiological impact. In Proceedings of the GEAPS Exchange Conference, Austin, TX, USA, 27 February-1 March 2016; Grain Elevator And Processing Society: Golden Valley, MN, USA, 2016.

10. Issa, S.F.; Field, W. How 'safe' is grain bin fall-safety equipment? A review of entrapment cases where such equipment was used. In Proceedings of the International Society of Agricultural Safety and Health (ISASH) Conference, Normal, IL, USA, 20-24 June 2015; ISASH: Charles Town, WV, USA, 2015.

11. Occupational Safety and Health Administration (OSHA). Fall Protection Systems Criteria and Practices; OSHA Publ. No. 1926.502; OSHA: Washington, DC, USA, 2008.

(c) 2017 by the authors. Licensee MDPI, Basel, Switzerland. This article is an open access article distributed under the terms and conditions of the Creative Commons Attribution (CC BY) license (http:/ / creativecommons.org/licenses/by/4.0/). 